\title{
OVERVIEW OF UAV ACTIVITIES IN WAGENINGEN UNMANNED AERIAL REMOTE SENSING FACILITY
}

\author{
Juha Suomalainen ${ }^{\mathrm{a}, *}$, Niels Anders ${ }^{\mathrm{b}, \mathrm{e}}$, Jappe Franke ${ }^{\mathrm{c}}$, Harm Bartholomeus ${ }^{\mathrm{a}}$,Corjan Nolet ${ }^{\mathrm{b}}$, Marinka van Puijenbroek ${ }^{\mathrm{d}}$, \\ Henk Kramer $^{c}$, Saskia Keesstra ${ }^{b}$, Sander Mücher $^{c}$, Lammert Kooistra $^{a}$ \\ ${ }^{\text {a }}$ Laboratory of Geo-Information Science and Remote Sensing, Wageningen University, The Netherlands \\ ${ }^{\mathrm{b}}$ Soil Physics and Land Management Group, Wageningen University, The Netherlands \\ ${ }^{\mathrm{c}}$ Alterra, The Netherlands \\ ${ }^{\mathrm{d}}$ Nature Conservation and Plant Ecology Group, Wageningen University, The Netherlands \\ ${ }^{\mathrm{e}}$ Institute for Biodiversity and Ecosystem Dynamics - Computational Geo-Ecology, University of Amsterdam, The Netherlands
}

\section{UAV-G 2015, Toronto, Canada}

KEY WORDS: UAV, UARSF, Hyperspectral, Orthophoto, DSM

\begin{abstract}
:
The WUR Unmanned Aerial Remote Sensing Facility (UARSF) (www.wageningenur.nl/uarsf) is a co-operation organization of different groups within Wageningen University and Research Centre to use UAVs in remote sensing applications. The facility was founded in 2012. Since then the facility has taken part in numerous of mapping campaigns exploiting UAVs with researchers with in WUR as well as external cooperating partners. In this paper/poster we present the facility, the UAV platforms, the camera systems, and demonstrate some highlights of our results.
\end{abstract}

\section{MOTIVATION}

The objective of the WUR UARSF is threefold:

(1) To develop innovation in the field of remote sensing science by providing a platform for dedicated and high-quality experiments;

(2) To support high quality UAS services by providing calibration facilities and disseminating processing procedures to the UAS user community;

(3) To promote and test the use of UAS in a broad range of application fields like habitat monitoring, precision agriculture and land degradation assessment.

The facility is hosted by the Laboratory of Geo-Information Science and Remote Sensing (GRS) and the Department of Soil Physics and Land Management (SLM) of Wageningen University together with the team Earth Informatics of Alterra.

\section{UAV PLATFORMS AND CAMERA SYSTEMS}

The UARSF has currently two types of UAV platforms: two Aerialtronics Altura AT8 octocopter UAVs and a Mavinci fixed wing UAV. The Altura provides a flexible platform to perform small scale remote sensing experiments with varying sensors and high control over the view positions. The Mavinci allows operation mapping of large areas with an integrated camera system for automated production of orthophotos and digital terrain model. The Altura platform allows different sensor types to be attached up to a weight of $2.0 \mathrm{~kg}$ with the following camera types available:
- High-resolution orthophoto camera system;

- Hyperspectral Mapping System (HYMSY) in range $400-1000 \mathrm{~nm}$ with $10 \mathrm{~nm}$ spectral resolution. (Suomalainen, 2014)

- $\quad$ Multispectral Mapping System (MUMSY) with bands [DeepBlue, Blue, Green, Red, NIR]; [2]

- A Rikola hyperspectral camera with Fabry-Perot adjustable filter.

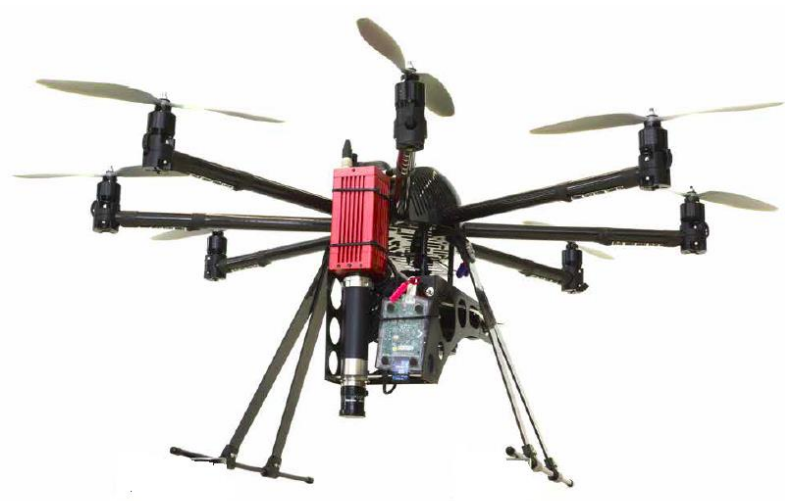

Figure 1. Aerialtronics Altura AT8 octocopter UAV with HYMSY sensor

* Corresponding author (juha.suomalainen@wur.nl) 


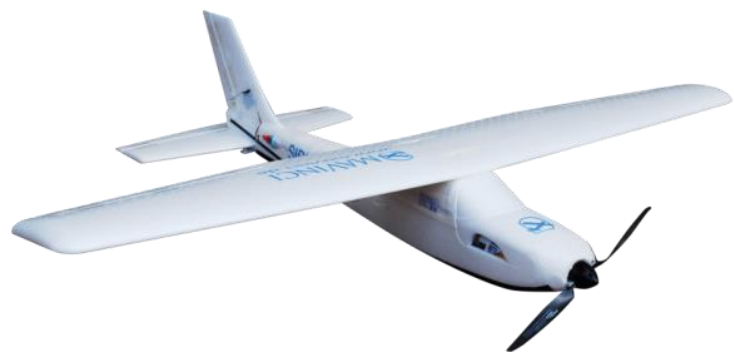

Figure 2. Mavinci fixed wing UAV

Next to the camera systems, processing facilities have been developed for automated processing of the acquired image datasets to calibrated and georeferenced data products. From this high-quality products like Digital Surface Models, RGB Orthomosaics and Hyperspectral data Cubes can be derived which will be adopted for research in different application fields.

\section{CAMPAIGNS}

During the last couple of years UARSF has taken part in numerous mapping campaigns under topics of precision agriculture (Netherlands, Rwanda, Germany, Philippines, see figure 3), soil erosion (Spain), forestry (Netherlands, Indonesia, Guyana, see figure 4), dune growth (Netherlands), habitat monitoring (Netherlands), and coral reef mapping (Bonaire, see figure 5). Highlights of these campaigns will be presented in a poster in this conference.

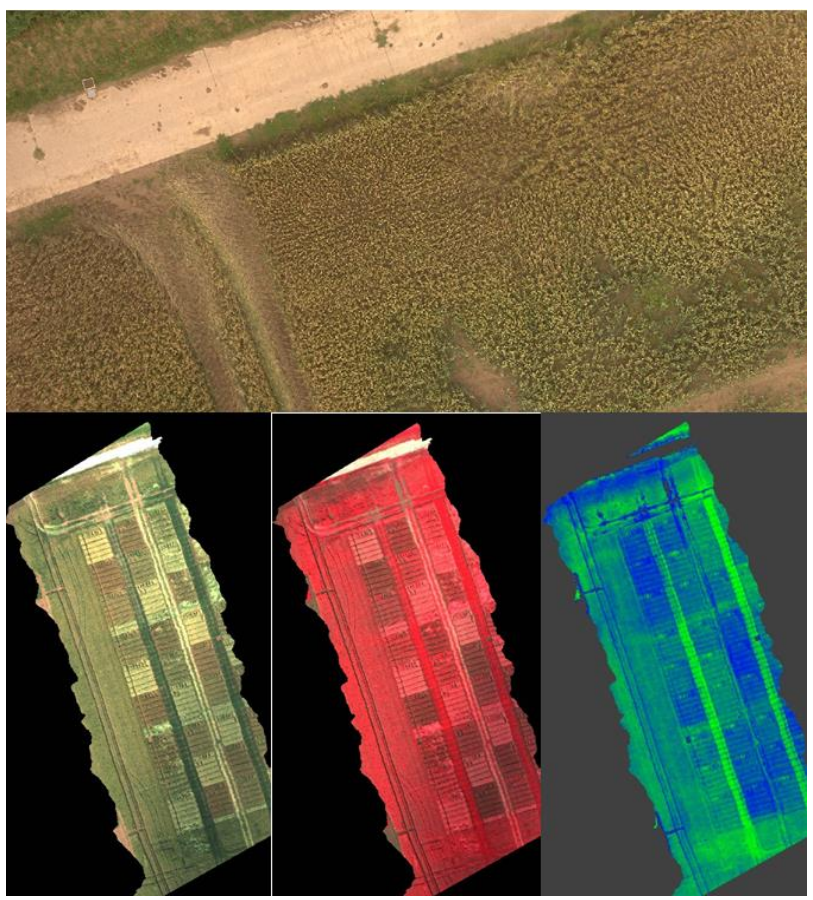

Figure 3.A view of data in a precision agriculture experiment. (top) High resolution RGB orthomosaic, (bottom) RGB, False color and NDVI visualizations of hyperspectral data

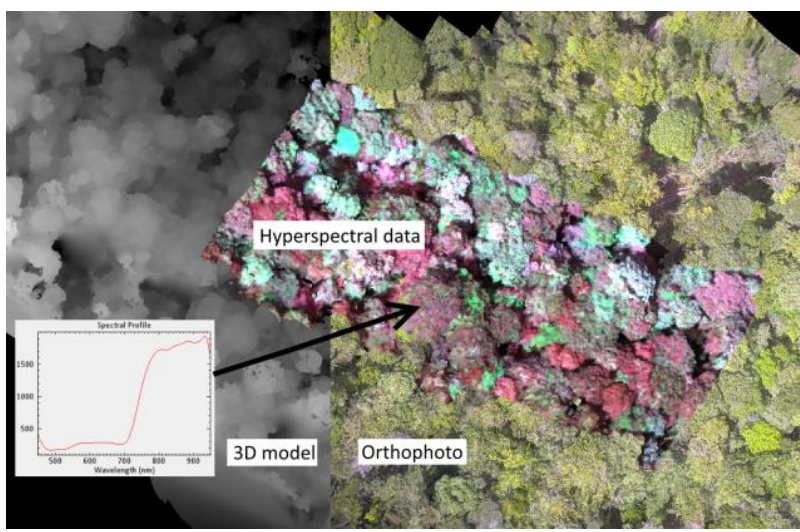

Figure 4. Fused RGB, 3D structure, and hyperspectral data of Guyanese rain forest

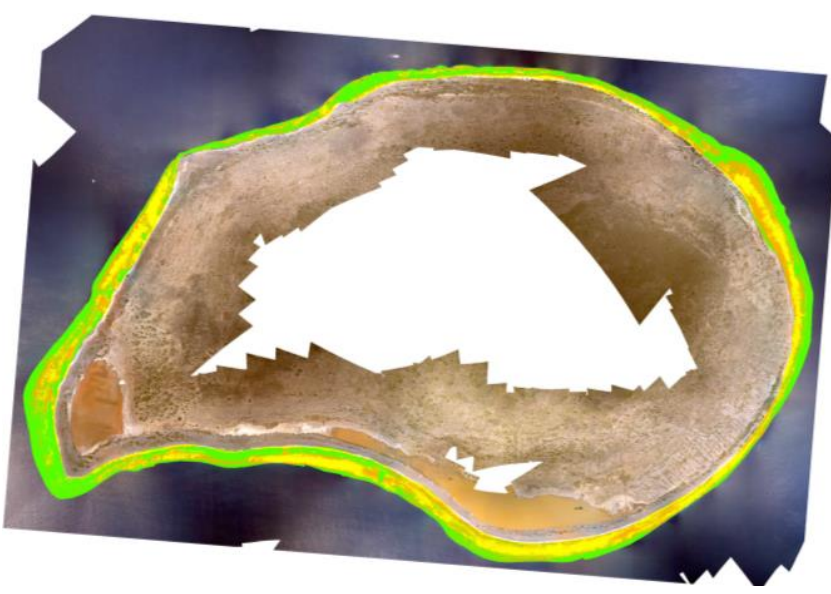

Figure 5. Coral reef map of Klein Bonaire island (Groeneveld, 2014)

\section{REFERENCES}

WUR Unmanned Aerial Remote Sensing Facility website: www.wageningenur.nl/uarsf

Suomalainen, J., Anders, N., Iqbal, S., Roerink, G., Franke, J., Wenting, P., Hünniger, D., Bartholomeus, H., Becker, R. \& Kooistra, L., "A Lightweight Hyperspectral Mapping System and Photogrammetric Processing Chain for Unmanned Aerial Vehicles", Remote Sensing, 2014, 6, 11013-11030. doi:10.3390/rs61111013

Groeneveld, IJ, "Classification of the reef zone around the island of Klein Bonaire", MSc thesis, Wageningen University, 2014 